\title{
PREMIO NUEVA CULTURA DEL TERRITORIO, MODALIDAD DE GESTIÓN
}

Madrid, 30 de mayo de 2019

PERE SALA I MARTÍ

Director del Observatorio del Paisaje de Cataluña

Presidenta del Colegio de Geógrafos,

Presidente de la Asociación Española de Geografía

autoridades académicas,

amigas y amigos,

Buenas tardes y muchas gracias por concedernos la VI edición del Premio Nueva Cultura del Territorio. Este Premio significa mucho para nosotros. Y también significa mucho para el paisaje, y para todas personas, entidades, instituciones o investigadores que estudian, trabajan o creen en el paisaje. Y por esto quiero reiterar nuestro sincero agradecimiento a las dos entidades que impulsan este Premio.

Gracias, Joan (Nogué), por una presentación que me deja sin palabras, y por tu amistad y apoyo constantes.

Coincidir con Joan Nogué es un privilegio y un honor. Y más aún cuando lo echamos de menos. Pero coincidir aquí hoy tiene más significado que nunca, ya que Joan ha sido invitado como presentador del Premio, y es a la vez premiado.

Porque es él, como saben, quien imaginó, creó y pilotó el Observatorio desde el principio, en el año 2005. Creo que no es necesario recordar en este foro lo que significa Joan Nogué para todos: es un referente en el pensamiento contemporáneo de paisaje, y está reconocido como una de las mentes más lúcidas y vanguardistas en este campo. Y también nos ha seducido su especial sensibilidad 
para apoyar e implicarse en iniciativas y experiencias de paisaje surgidas desde la ciudadanía y que apuntan hacia formas de gobernanza colectiva del territorio. De ahí que el Observatorio estemos siempre presentes de una forma u otra en campos de batalla de todo tipo.

Joan creó un equipo de trabajo (que hoy está aquí, y estoy muy contento de que hayan venido) de una excelente calidad humana. Son personas con un gran compromiso, vocación, profesionalidad y una gran capacidad de trabajo. Fue como crear aquellas recetas maestras, en las que la selección de los ingredientes y la forma como se organizan y se ordenan da resultados extraordinarios. Ni un ingrediente más, ni uno de menos. Es un equipo que funciona por si solo, y esto no se encuentra cada día. La pericia y el acierto que tuvo Joan para montar este equipo son virtudes que reúnen muy pocas personas, y que se lo agradeceremos eternamente. Es un equipo, dicho sea de paso, de siete personas, aunque precisamente por su dedicación y pasión, ¡más de uno ha pensado alguna vez que somos quince!

Los miembros del equipo que hoy estamos aquí (Jordi Grau, Laura Puigbert -geógrafa-, Montse Vila) y las otras tres personas que no han podido acompañarnos (Gemma Bretcha, Anna Jiménez - también geógrafa- y Anna Montero) hemos tenido el privilegio de crecer y de formarnos al lado de Joan. Nos ha hecho de maestro, y dos años después de dejar la dirección nos esforzamos por encima de todo en asegurar la continuidad de los valores que él mismo inyectó en el Observatorio y que llevamos 14 años defendiendo.

En mayo de 2017 Joan escribió un texto en nuestro boletín "Paisaj-e" que terminaba así: "Seguiré trabajando en temas de paisaje y para el paisaje con la misma ilusión y pasión de siempre, pero ahora desde otras trincheras. Gracias". Gracias a ti, Joan, de todo corazón. En paisaje, tus trincheras son también las nuestras. Te llevamos siempre con nosotros, estemos en las que estemos.

Me he permitido empezar hablando de Joan Nogué y del equipo del Observatorio porqué, a decir verdad, cuando ayer preparaba estas palabras, mi discurso no me salía de otra forma. Con Joan, no solo hemos tenido el privilegio de compartir durante 12 años su sabiduría, compromiso, persistencia y generosidad, sino que además hoy podemos celebrar juntos el Premio que recibe el Observatorio.

Lo decía al empezar: Es para nosotros un gran honor recibir el Premio Nueva Cultura del Territorio. Nos sentimos muy orgullosos y felices por este importante reconocimiento, de un Premio que es cada vez más prestigioso a nivel del Estado. Queremos agradecer al Col-legi de Geògrafs por haber presentado la candidatura 
del Observatorio, a los miembros del jurado el haberla seleccionado, y a la Asociación Española de Geografía y al Colegio de Geógrafos por su concesión.

Fueron estas dos entidades junto con otros expertos en urbanismo quienes en el año 2006 impulsaron el "Manifiesto por una Nueva Cultura del Territorio, que nos sirvió -y nos sigue sirviendo conceptualmente- como guía hoy aún.

El Manifiesto coincidió aproximadamente con la creación del Observatorio, y fue también en el mismo período en el que Julio Llamazares, galardonado también esta tarde, escribía en un artículo en el diario El País: "Cierto que muchas personas lo consideran fundamental para su realización vital y que hay artistas que han hecho de él el motivo central de sus creaciones, pero, por lo general, al español el paisaje le resulta indiferente, cuando no directamente un obstáculo para sus pretensiones de desarrollo, que circunscribe normalmente a lo económico."

Pues bien, el Observatorio se concibió precisamente como una respuesta a este desafío. Se entendió como un proyecto colectivo y transversal, y se le otorgó en aquel momento poca capacidad decisoria, pero sí una importante capacidad de generación de conocimiento y de creación de sinergias, complicidades e interdependencias, desde la proximidad y la experiencia cotidiana. Y estos activos son los que nos permiten: seguir asesorando a la administración (a todos los niveles); generar conocimiento y metodologías desde la interdisciplinariedad, y con todos los sectores profesionales y todas las disciplinas que trabajan en temas de paisaje; ser un punto de encuentro entre amplios sectores de la sociedad (académico, político, profesional, social, cultural, económico); fomentar la creación de espacios de diálogo y cooperación entre el gobierno y la sociedad civil y entre la esfera pública y la privada; actuar como un vivero de proyectos innovadores; detectar y promover el debate sobre temas emergentes (ahí está, por tanto, un centro que busca influir en la definición y el diseño de las tendencias de futuro); incluir prioridades paisajísticas en la agenda política; ser una antena en el mundo y una antena del mundo en nuestro territorio; y promover la formación, educación y la sensibilización.

No pasa siempre que se impulse un organismo específico que tenga la tarea de colaborar con la administración en la implementación de las políticas de paisaje, y esta es una singularidad que se ha demostrado operativa, y es a la vez muy valorada en el contexto internacional.

Catálogos de paisaje, cartas y planes de paisaje, proyectos, documentos con criterios, simposios, jornadas, publicaciones... Éstas son algunas de nuestras herramientas de trabajo, que están demostrando que funcionen bien no solo para do- 
cumentar y orientar a las políticas públicas, sino también con fines pedagógicos y de sensibilización a la sociedad. Cada vez hay más territorios que buscan nuevos contenidos y nuevas respuestas, y que ven el paisaje cada vez más como un bien común, como un motor para su desarrollo, y como una vía para incrementar su nivel de autoestima, de identidad, así como la calidad de vida de las personas.

Hoy el paisaje afronta grandes temas: su contribución al bienestar, a la igualdad, a la cohesión, y la calidad de vida; su creciente rol dual como indicador y a la vez como respuesta al cambio climático (y esto toma más sentido que nunca en una situación de emergencia climática como la declaró hace pocos días el Gobierno de Cataluña); las dialécticas local-global, rural-urbana, autenticidad versus artificialización, o transformación versus destrucción; la cuestión de las identidades en un contexto de globalización y de hipermovilidad; la creación de nuevos paisajes referenciales; la relación entre el paisaje y el nuevo turismo; el bien común; los límites de la ciudad; la democracia participativa (en un momento en que debemos abrir los ojos a nuevas formas de gobierno del territorio y del paisaje que están surgiendo, porqué serán cada vez más necesarias, y están marcando un camino de futuro); o los paisajes virtuales, que trataremos el próximo mes de otoño.

Recordando de nuevo las palabras de Julio Llamazares en el artículo antes mencionado, sobre la poca importancia que el ciudadano da al paisaje, probablemente no podamos afirmar que años después la situación haya cambiado radicalmente, pero es cierto que poco a poco la conciencia ciudadana crece. Lo estamos notando cada vez más. El debate de los últimos veinte años sobre el cambio climático, la problemática ambiental, la sostenibilidad, la escasez de recursos naturales, o el empobrecimiento de nuestros paisajes, lentamente hacen ver a la población que las cosas deben hacerse de otra manera.

Ahora bien, a pesar de que la próxima semana se cumplirán 14 años de la aprobación de la Ley del paisaje por parte del Parlamento catalán, el paisaje "apenas" comienza a penetrar en el debate ciudadano y político y, por tanto, la tarea de sensibilización y concienciación que nos queda por delante es ingente. Hay que recordar que cuando hablamos de paisaje no sólo nos estamos refiriendo a su papel capital en el ámbito de la ordenación del territorio, sino que estamos hablando también de patrimonio, de cultura, de economía, o de identidad territorial, a todas las escalas, de la nacional a la local. Sin ir más lejos, este próximo lunes empezará un curso de paisaje de cinco días que hemos organizado para los cargos electos y los técnicos de la administración local. Impulsar la formación de los cuadros locales es fundamental para seguir cambiando determinadas mentalidades y formas de hacer. 
Finalmente, no puedo terminar estas palabras sin agradecer a quienes nos están acompañando en este camino. Los 14 años del Observatorio se han llenado de compañeros, amigos y cómplices de viaje, de aquí y de muchas partes del mundo, desde Latinoamérica hasta Japón, pasando por Europa. Los que nos conocen saben que el trabajo que hemos hecho no hubiera sido posible sin la contribución de muchas de estas personas, y que todas han contribuido a que el Observatorio haya ido creciendo y consolidándose.

Nos hace enormemente felices compartirlo hoy aquí con algunas de estas personas. El apoyo del Departamento de Geografia de la Universidad de Girona, y de su director, Joan Vicente, ha sido imprescindible. O no hay semana que en el Observatorio no se nombre por algún motivo u otro al profesor Florencio Zoido y al Centro de Estudios Paisaje y Territorio, o al profesor Rafael Mata, y a tantas otras personas que a lo largo de estos años se han ocupado de inspirarnos e inyectarnos pasión por el paisaje, nos han dado aporte intelectual, nos han ayudado a pensar y a mirar de otro modo el territorio, o nos han dado algo más importante: apoyo emocional y afecto. Este Premio también es para ellos.

La trayectoria del Observatorio tampoco hubiera sido posible sin las organizaciones que han creído en nosotros y nos han apoyado, empezando por los cinco diferentes Consejeros de Territorio - de diferente color político- que han presidido el Consejo Rector, sus miembros, a la ciudad de Olot, que nos acoge con mucha generosidad, y a todas las personas y entidades que están desarrollando una tarea encomiable y tenaz desde cada punto del territorio, nadando en tantas ocasiones a contracorriente de los contextos que les rodean.

Sin ellas nuestro trabajo no tendría sentido. Este Premio reconoce y prestigia también su encomiable tarea.

Cuando iniciamos nuestro trabajo en el Observatorio del Paisaje jamás imaginamos que hoy estaríamos aquí recogiendo un Premio de este calado y con este significado. Recibiéndolo renovamos nuestro compromiso con el paisaje, y nos aporta la energía necesaria para asumir con mayor determinación los desafíos que colectivamente afrontamos.

Muchas gracias. 


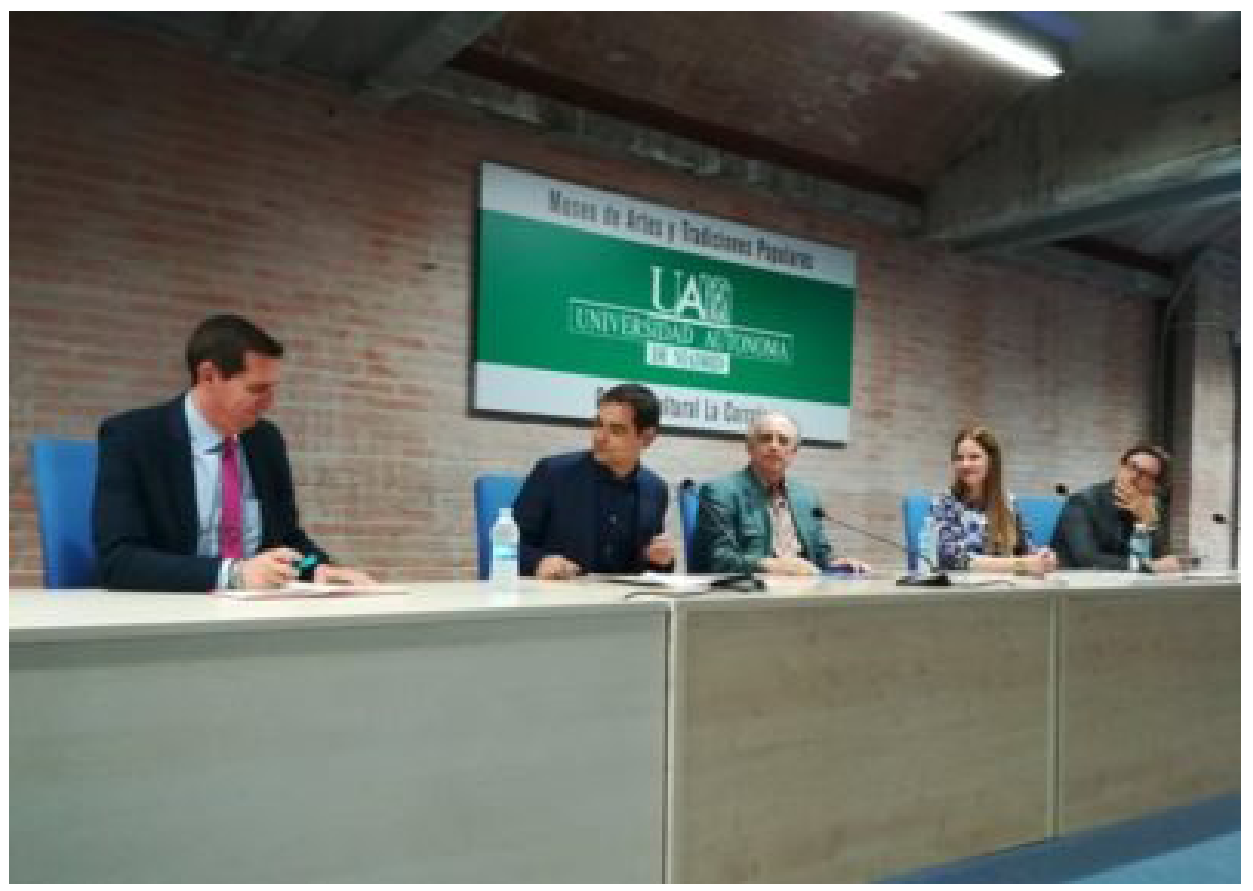

Intervención de Pere Sala, del Observatorio del Paisaje, Premio NCT en la modalidad de Gestión Fotografia: AGE y Colegio de Geógrafos 